\title{
Riva Palacio en la España editorial
}

Héctor Perea

IIF-UNAM

La estancia de Riva Palacio en Madrid es más que un conjunto de anécdotas del mundillo intelectual; es el antecedente de la labor literaria de otros mexicanos en

España, como Martín Luis Guzmán y Alfonso Reyes.

$\mathbf{L}$

a historia del último cuarto del siglo XIX en México y en España deva necesariamente al recuerdo de cuando menos dos figuras que resultaron fundamentales para consolidar las relaciones modernas entre ambos países; figuras no siempre recordadas hoy con el peso que tuvieron: Emilio Castelar, por el lado hispano, y Vicente Riva Palacio, por el mexicano. Ya en otro artículo vi de forma detallada la vida que Riva Palacio llevó en la península. 'Las funciones políticas y

1 Véase "Exilio", 1995. diplomáticas las ejerció éste sin descuidar nunca las humanas, las que se ejemplificaban sobre todo en tres espacios donde, además, se plantearian y asentarian los cambios inminentes de la España de entonces: los salones aristocráticos, las cortes y las tertulias de café. Extensiones de los mismos serían desde luego las redacciones de periódicos y revistas, así como las oficinas de las editoriales del momento. En muchas de ellas Riva Palacio llegó a ser, como Francisco A. de Icaza y Juan de Dios Peza por entonces, y años después Alfonso Reyes, una presencia ineludible. 
En su Autobiografía, Rubén Dario describió de la siguiente forma la presencia del general en la vida española:

Era el alma de las delegaciones hispanoamericanas el general don Juan (sic) Riva Palacio, ministro de Méjico, varón activo, culto y. simpático. En la corte española el hombre tenía todos los merecimientos; imponía su buen humor y su actitud, siempre laboriosa, era por todos alabada [...]

Tenía don Vicente, en la calle de Serrano, un palacete lleno de obras de arte $y$ antigüedades, en donde solía reunir a sus amigos de letras, a quienes encantaba con su conversación chispeante y la narración de interesantes anécdotas. Era muy aficionado a las zarzuelas del género chico y frecuentaba, envuelto en su capa clásica, los teatros en donde habia tiples buenas mozas. Llegó a ser hombre popular en Madrid. ${ }^{2}$

La legación mexicana estaba por entonces muy cerca de la casa de Castelar, ubicada en la misma calle de Serrano, número 40 . En el palacete del político español -que había aprendido del amigo y asesor de Justo Sierra, Telésforo García, a cocinar platillos mexicanos-también se llevaba a cabo una tertulia donde Riva Palacio conoció a políticos liberales y monárquicos, a obispos, a condesas y escritores. Otro Serrano, Pedro, biógrafo del diplomático mexicano, recordaba que "Cánovas y Castelar eran los más ame. nos conversadores de su época". Y, en relación con la amistad y admiración que el general guardaba con el segun-

\footnotetext{
2 Citado en Maria Isabel Hernández Prieto, "Escritor", 1993, pp. 109-110.
}

do, agregaría: "Al general Riva Palacio le encantaba la charla del inmenso tribuno, de imaginación tan volcánica que hablaba de los tiempos prehistóricos de la China al discutir en el Parlamento los presupuestos del Reino." 3

Independientemente de las actividades sociales y políticas desarrolladas por Vicente Riva Palacio en Madrid, a continuación quisiera referirme sólo a la imagen que Riva Palacio proyectó, y a la participación que tuvo, en algunos medios impresos españoles e hispanoamericanistas de enorme importancia en el momento cultural y político de la península. En particular, en dos de éstos: La España Moderna y La Ilustración Española y Americana. En la última, por cierto, aparecería la primera versión de buena parte de Los cuentos del general, obra póstuma, como libro, del mexicano. En esta idea de anticipar los volúmenes a la prensa en forma de colaboraciones así como en el propio gusto por la aventura revolucionaria, el general habría de anteceder a Martín Luis Guzmán, con El águila y la serpiente, La sombra del caudillo, Javier Mina, héroe de España y de México y Filadelfia, paraíso de conspiradores y otras historias noveladas, obras clave del segun. do, y que tendrian también su primer acercamiento al lector por medio de la prensa.

Riva Palacio llegó a España el mismo año que Manuel Payno, es decir en 1886. Aunque, a diferencia de éste, bajo la impronta, luego extendida a otros intelectuales mexicanos, del exilio

${ }^{3}$ Pedro Serrano, Silueta, 1934, p. 56. 


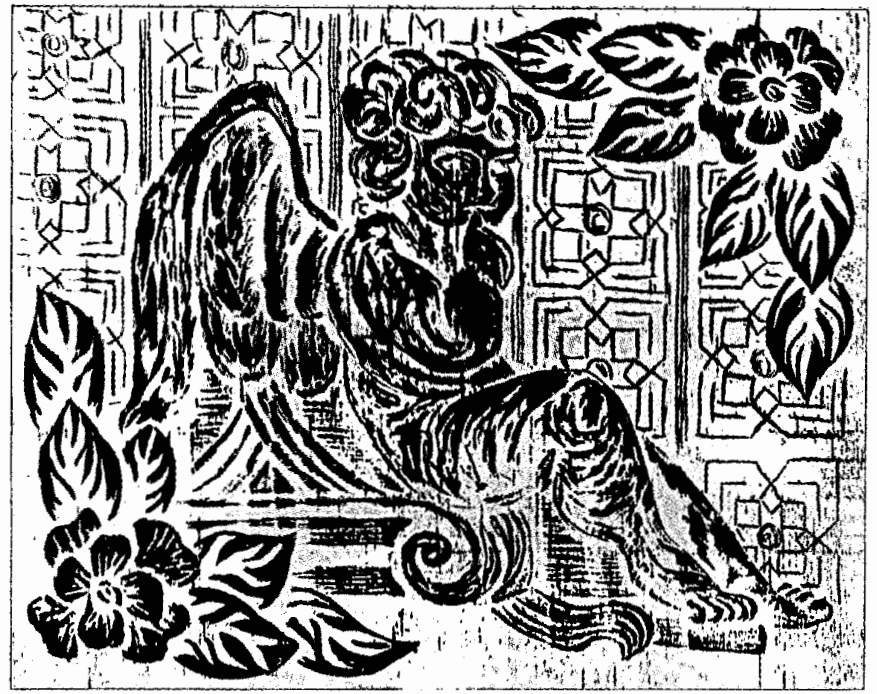

diplomático. Dos años después aparecería en La Ilustración Española y Americana, como una primera colaboración, el poema "Dos cartas". Al año siguiente, su nombre se volvería una presencia cotidiana para los lectores del otro gran proyecto hispanoamericanista madrileño: La España Moderna. Pero antes de referirme a la participación que Vicente Riva Palacio tuvo en estos dos espacios, habría que considerar, para mejor aquilatar la variada actividad intelectual del mexicano, que en ese mismo 1889 publicó en $M a$ drid Cómico, que se anunciaba como "periódico semanal, literario, festivo, ilustrado", su narración "Problema irresoluble", luego recogido en Cuentos del general. Cabría agregar que el proyecto de Madrid Cómico, dirigido por el poeta Sinesio Delgado -y donde encontraremos también colaboraciones de Francisco A. de Icaza-, equiparaba en importancia la labor de los escritores y la de los viñetistas. En su portada, constituida por un caricaturista de cuerpo entero y un cuarteto chusco, a manera de pie de ilustración, veremos retratados a algunos de los amigos de Riva Palacio y de otros tantos mexicanos radicados en España, como el cubano Emilio Bobadilla (que firmaba con el pseudónimo de Fray (andil), Joaquín Dicenta o el propio Delgado.

En 1890, Riva Palacio iniciaría sus colaboraciones en El Álbum Ibero Americano con su poema "Al viento". Como directora de esta revista figuraba la novelista Concepción Gimeno 
de Flaquer, escritora aragonesa muy conocida en México y que había vivido largos años en este país. ${ }^{4} \mathrm{En} E l{ }^{\prime}$ Álbum Ibero Americano la firma de Riva Palacio apareció al lado de la de otros mexicanos como Ignacio Manuel Altamirano, Gustavo Baz, Agustín F. Cuenca o Salvador Díaz Mirón. Otros tantos autores españoles cercanos a México fueron también colaboradores asiduos de la revista dirigida por $\mathrm{Gi}$ meno de Flaquer. En este sentido, cabría destacar los nombres de Blanca de los Ríos de Lampérez y de Salvador Rueda. La primera, directora a su vez de la revista Raza Española, de la editorial Calleja, sería reseñista de libros de Francisco A. de Icaza así como amiga de Carlos Pereyra. Su esposo, el arquitecto y arqueólogo Vicente Lampérez y Romea, escribió también sobre arquitectura virreinal mexicana en Raza Española. Por su lado, Salvador Rueda fue contertulio de Luis G. Urbina, amigo de Icaza y prologuista de un libro olvidado del periodista mexicano Luis Andrade; pero, además, sería tema del primer artículo que Amado Nervo envió a México desde España.

El año anterior, 1889, habían aparecido en las páginas de La España Moderna. Revista Ibero-Americana tres colaboraciones de Vicente Riva Palacio, dos poemas y una carta dirigida al político, poeta y periodista satírico extremeño Vicente Barrantes. ${ }^{5}$ La Es-

${ }^{4}$ Hernández Prieto, "Escritor", 1993, p. 106.

${ }^{5}$ El periódico que fundó y prácticamente escribía por completo, llevaría como cabecera un nombre muy del gusto de Riva Palacio, Las píldoras. Los pseudónimos que llegó a utilizar no se quedarian atrás en cuanto a ingenio: Publicio y El Abate Rascarrabias. paña Moderna nacía como una revista mensual y su director propietario era el coleccionista y editor José Lázaro y Galdiano. Si, como ya mencioné, Riva Palacio anunció una de las características de la actividad literaria hispana de Martín Luis Guzmán al dar anticipos de sus libros a la prensa, ${ }^{6}$ también antecedería a Alfonso Reyes en cuanto a la participación, desde su inicio, en algunos de los proyectos editoriales españoles más importantes de su tiempo. ${ }^{7}$ La España Moderna, publicación que sobreviviría hasta 1914, ya desde 1894 habría de cambiar su tono hispanoamericanista para volverse, como lo señalaba el nuevo subtítulo, Revista de España. Durante los seis años anteriores no obstante, los nombres de Rubén Darío, Jorge Isaacs, Joaquín García Icazbalceta, Francisco Sosa o el propio Riva Palacio compartirían el espacio impreso con Emilia Pardo Bazán, Clarín, Armando Palacio Valdés o Juan Valera.

La carta de Riva Palacio alli aparecida, dirigida al también historiador Barrantes y referida a opiniones de éste sobre América, iba acompañada de otras dos misivas de Cesáreo Fernández Duro, escritor y marino zamorano que años antes había participado en una expedición contra México, y de Espada y Zaragoza, autores que, como Riva

${ }^{6}$ La diferencia entre una y otra postura estaría, sin embargo, en el hecho de que, al contrario del diplomático, Guzmán requería, para su subsistencia, además de las regalías, el cobro de las publicaciones semanales.

${ }^{7}$ Reyes figuró, bajo esta condición de iniciador, en cuando menos dos de los proyectos de José Ortega y Gasset, los más importantes del momento: España y El Sol. 
Palacio, según aseguraba un redactor anónimo de la publicación, gozaban de "verdadera y grande autoridad en las cuestiones ultramarinas". En ella, Riva Palacio se refería a un ensayo publicado por Vicente Barrantes en junio de 1889 en La España Moderna, dentro de la "Sección hispano-ultramarina", donde el español había escrito, decía el general, "a impulso del noble deseo de unir a todos los hombres de nuestra raza".

Todos los americanos -concluiría entonces Riva Palacio- estamos unidos por un vínculo que es una virtud nueva en el mundo, y de la que no ha dado hasta hoy ejemplo la historia: el patriotismo continental.

Nadie nos lo inventó ni nos lo enseñó, ni de parte alguna lo hemos copiado. Sin previo acuerdo, sin propaganda, sin que los periódicos siquiera se ocupen de eso, el patriotismo continental existe en la América: es cada día más vigoroso, y acabará por hacernos muy fuertes. ${ }^{8}$

Las otras colaboraciones del general aparecidas en La España Moderna fueron dos poemas referidos también a asuntos de México, "Lorencillo. Episodio histórico-año de 1683 "9 era una historia de piratas acontecida en Vera. cruz; en "Sor Magdalena. Tradición mexicana",10 Riva Palacio acudiría

8 Vicente Riva Palacio, "Sección hispano-ultramarina. Excmo. Sr. D.V. Barrantes", La España Moderna, Madrid, año I, núm. 7, julio 1889, pp. 127-129.

${ }^{9}$ La España Moderna, año I, marzo 1889 , pp. 146-160. 126.

${ }^{10} \mathrm{Ibid}$, año 1 , núm. 7 , julio 1889 , pp. 115.

Riva Palacio en la España editorial igualmente, como en el caso de la invasión al puerto, a la imagen de unas naves, aunque en esta ocasión a las de una iglesia y convento, para acercanos las pasiones del cielo y de la tierra que ahogarían a una monja enamorada.

La manera en que figuraba el crédito en ambas publicaciones resulta sintomática en cuanto a la imagen que Riva Palacio tenía y tendría en España. En la primera se mostraba únicamente como el héroe liberal ("El General Riva Palacio"). Al final de "Sor Magdalena" aparecería, junto con la referencia anterior, un breve aunque significativo agregado: "C. de la Academia Española". Y es que el general, apenas desembarcado en España, había sido propuesto por el dramaturgo y bibliotecario perpetuo de la Academia, personaje cercano a Peza, Manuel Tamayo y Baus, para ser admitido dentro de la Real como académico correspondiente, hecho que se concretó a través del consenso unánime que resultaría de la acostumbrada votación secreta. ${ }^{11}$

Tiempo después, en noviembre de 1893, F.F. Villegas comentaría en $L a$ España Moderna, a vuela pluma, la aparición de un volumen de poemas de Riva Palacio. ${ }^{12}$ El autor de la nota en que se mencionaba la aparición de varios más no refería el título del libro del general, pero podemos pensar que se trataba del viejo recuento Mis ver. sos, de 1885, reeditado en Madrid ocho años después de su primera aparición

11 Véase Hernández Prieto, "Escritor", 1993, p. 103.

12 F. Francisco Villegas, "Impresiones literarias", La España Moderna, Madrid, año v, núm. LIX, noviembre 1893, p. 207. 
y tres antes de la muerte de Riva Palacio, en esta ciudad. En Mis versos, el general recogió los poemas publicados en La España Moderna y El Álbum Ibero-Americano.

A pesar de la importancia que $L a$ España Moderna tuvo en la difusión de la literatura y el pensamiento de $\mathrm{Vi}$ cente Riva Palacio en la península -recordemos que era ministro representante de México ante los gobiernos de España y Portugal-, fue otro medio hispanoamericanista el que, por un lado, había dado el apoyo inicial a la presencia física del general, $y$ por otro, brindaría una cobertura casi ilimitada a los distintos géneros de que éste se ocupó en la península. Y fue La llustración Española y Americana, tabloide frecuentado también, desde luego, por Emilio Castelar.

Esta publicación, una de las de mayor relevancia en la época, fundada en 1869 y que se editaría hasta 1921 , vino a ser una continuación de otra con la cabecera de El Museo Universal. ${ }^{13}$ Además de haber sido uno de los primeros medios que saludaron con entusiasmo la llegada a España de Riva Palacio, ${ }^{14}$ allí, repito, aparecería un poema suyo, "Dos cartas", 15 en 1888. Pero, como he venido haciendo, antes de referirme a las colaboraciones primeras del general en La Ilustración Española y Americana quisiera brin-

13 Hernández Prieto, "Escritor", 1993, p. 108.

${ }^{14}$ Véase Clementina Díazy de Ovando, "Prólogo", en Riva Palacio, Cuentos del general, 1986, p. IX.

${ }^{15}$ La Ilustractón Española y Americana (en adelante LIEA), Madrid, año XXXII, núm. I, 8 enero 1888 , pp. 26-27. car casi un lustro hacia adelante para comentar una forma distinta del reflejo intelectual que, gracias a la prensa, tuvo Riva Palacio sobre el lector español.

En el año de 1892, como es sabido, se festejó en España el Cuarto Centenario del Descubrimiento de América. En ese momento Antonio Cánovas del Castillo presidía el Ateneo Científico, Literario y Artístico de Madrid. Amigo íntimo y, como político, admirado por Riva Palacio, ${ }^{16}$ Cánovas invitó al general a participar con una conferencia en el ciclo por él ideado bajo el título, quizá excesivo, de "Criterio histórico con que las distintas personas que en el Descubrimiento de América intervinieron han sido después juzgadas". El autor de "Mamá Carlota", anticipando, de nueva cuenta, la actividad que más disfrutaría otro intelectual mexicano radicado posteriormente en Madrid, Carlos Pereyra, leyó dentro del Ateneo, el 18 de enero de 1892, su conocida conferencia "Establecimiento y propagación del cristianismo en Nueva España".

La Ilustración Española y Americana recogería las ideas expresadas por Riva Palacio en el Salón de Actos del Ateneo a través de una larga reseña del acontecimiento firmada por Angel Stor, en que prácticamente se reprodu-

16 P. Serrano, Silueta, 1934, p. 55. Se sabe, gracias a Rubén Darío, que durante una fiesta diplomática ofrecida por el general Cánovas resolvió una situación tensa provocada por el hecho de que la reina regente de España, Maria Cristina, pariente de Maximiliano no perdonara el que Riva Palacio hubiera sido de los militares que lo enjuiciaron. 
cía la conferencia. ${ }^{17} \mathrm{El}$ complemento periodístico del acto sería una fotografía de Edgardo Debas en la que se retrataba de perfil al general. ${ }^{18}$

Además del poema citado, Riva Palacio daría a La Ilustración Española y Americana un artículo, "El padre Las Casas", ${ }^{19}$ y el cuento "La historia de los siete durmientes". ${ }^{20}$ El retrato más representativo del temperamento de Riva Palacio proyectado por esta publicación fue, sin embargo, el que aportarian diez de sus cuentos del general, publicados bajo el título que Ilevó este libro póstumo, entre el 15 de septiembre de 1892 y el 22 de diciembre del mismo año.

Precedidos por un encabezado escrito con los rasgos absolutamente singulares, románticos, de una tipografia concebida especialmente para el mexicano y que chocaba con las capitulares floridas con que en La Ilustración Española y Americana se iniciaban los grandes ensayos americanistas, los Cuentos del general fueron desplegándose en las páginas del tabloide como por su propia casa. Allí aparecieron por primera vez los siguientes títulos: "Amor correspondi-

17 LIEA, Madrid, año XXXVI, núm. XXVIII, 30 julio 1892 , pp. 58,59 y 62 . Ese mismo año, Riva Palacio habría de publicar una conferencia en forma de libro (Establecimiento y propagación del cristianismo en la Nueva España, Casas Sucesores de Rivadeneyra, Madrid, 1892).

${ }^{18} \mathrm{La}$ fotografia se repetirá, en 1896 , al morir el diplomático en Madrid.

${ }^{19}$ LIEA, Madrid, año XXXVI, núm. XXXXII, 8 octubre 1892, pp. 219 y 220.

${ }^{20}$ Ibid., año XL, núm. IX, 8 marzo 1896, pp. $139,140,142$ y 143 . do", 21 "Las mulas de su excelencia", 22 "El nido de jilgueros", 23 "La máquina de coser", 24 "Las madreselvas (cuento árabe)", 25 "Consultar con la almohada. Tradición mexicana", 26 "La bendición de Abraham",27 "Ciento por uno", 28 "Las honras de Carlos V" 29 y "La limosna".30

María Isabel Hernández Prieto menciona aun otras colaboraciones importantes de Vicente Riva Palacio, posteriores a 1892, en La Ilustración Española y Americana. Corresponden, nuevamente, a lo difundido por el Album Ibero-Americano. Entre las más valiosas y olvidadas están los artículos "A Colón. Un deseo" 31 y "Homenaje a José Zorrilla", así como el cuento, inédito en libro, "Los dos enjaulados". 32 Entre las creaciones ofre-

${ }^{21}$ lbid., año xxxyI, núm. XxxIv, 15 septiembre 1892 , pp. 158 y 159.

22 Ibid., núm. Xxxv, 22 septiembre 1892 , pp. 179 y 180. 199.

23 Ibid., núm. XXXVI, 30 septiembre 1892, p.

${ }^{24}$ Ibid., núm. xxxIx, 22 octubre 1892, p. 274.

25 Ibid., núm. XI, 30 octubre 1892, p. 290.

26 lbid., núm. xLI, 8 noviembre 1892, pp. 310 y 311 .

${ }^{27}$ Ibid., núm. XuII, 15 noviembre 1892 , p. 331.

28 Ibid., núm. XIII, 22 noviembre 1892, p. 351.

${ }^{29}$ Ibid., núm. XLV, 8 diciembre 1892, pp. 391 y 394.

30 Ibid., núm. XIVII, 22 diciembre 1892, p. 430.

${ }^{31}$ Véase Hernández Prieto, "Escritor", 1993, p. 110.

${ }^{32}$ La investigadora española observa que este relato no fue recogido por Clementina Díaz y de Ovando en su edición de los Cuentos del general, del año 1975. En ese volumen no figura tampoco, en su reedición de 1986, otro de los 
cidas en su momento al lector por esta publicación y que engrosarían sus libros, encontraremos "Duda y fe" (Mis versos) y "Sueño.y realidad" (Páginas en verso). Pero otra revista, Blanco y Negro, publicó todavía, en 1893 , los poemas del general "La vejez" y, de nuevo, "Al viento".

En la participación de Riva Palacio dentro de la prensa madrileña descubriremos otros rasgos que anticiparían el futuro desempeño de autores posteriores, como Martín Luis Guzmán, en éste y en otros medios. Tanto las obras como las vidas de estos mexicanos constituyeron en España ricas fuentes de inspiración para los políticos españoles y americanos; aunque también, desde una perspectiva no siempre menor, la editorial, para los ilustradores. ${ }^{33}$ En clara retribución, serían las calles y costumbres madrileñas las que más y mejor ilustraron los libros de generales mexicanos como Vicente Riva Palacio o Francisco L. Urquizo y de multitud de civiles exiliados, diplomáticos, paseantes que buscaban describir, a través de su propia escritura, la musculatura de la ciu- dad y de sus distintos universos. Y uno de los más importantes fue y ha sido, desde luego, el editorial.

\section{BiblogRAFIA}

-Hernández Prieto, María Isabel, "El escritor mexicano Vicente Riva Palacio en el Madrid del siglo XIX", Anales de Literatura Hispanoamericana, núm. 22, Madrid, 1993.

-Perea, Héctor, "El exilio mexicano entre dos siglos", Literatura Mexicana, núm. VI-1, 1995.

-Redondo, Gonzalo, Las empresas politicas de José Ortega y Gasset, Rialp, Madrid, 1970.

-Riva Palacio, Vicente, Cuentos del general, edición y prólogo de Clementina Díaz y de Ovando, Editorial Porrúa, México, 1986 ("Sepan cuántos...", 101).

-Serrano, Pedro, Silueta del general, [s.p.i.], 1934.

\section{HEMEROGRAFía}

-La España Moderna.

-La Ilustración Española y Americana. cuentos que menciono arriba: "La historia de los siete durmientes".

${ }^{33}$ Recordemos que uno de los elementos que habría de provocar un mayor desgaste en la imagen que proyectaba el gobierno de la II
República fueron las ácidas ilustraciones y caricaturas con que los medios impresos acompaña. ron las críticas políticas a Manuel Azaña. Al respecto, véanse las reproducciones del libro de Gonzalo Redondo, Empresas, 1970. 